\title{
NERVE ROOT COMPRESSION IN SPONDYLOLYSIS AND SPONDYLOLISTHESIS
}

\author{
J. G. EDELSON, H. NATHAN
}

From the Poriya Hospital, Tiberias, and the Sackler Medical School, Tel Aviv

\begin{abstract}
Thirty-four bony specimens of isthmic spondylolysis were examined and, in a significant number $(32 \%)$, stenosis of the intervertebral foramen was noted. Although not emphasised in previous reports, this finding may be an important factor in the aetiology of nerve root compression when this is associated with spondylolysis and spondylolisthesis. Anatomical guidelines for adequate surgical decompression are suggested.
\end{abstract}

We have examined 34 skeletal specimens of isthmic spondylolysis, to our knowledge the largest group of specimens reported in the orthopaedic literature. The pathoanatomy is surprisingly consistent and helps to explain the radicular involvement sometimes seen in this disorder. It confirms our clinical impression, shared by some (Newman 1973; Helfet and Gruebel Lee 1978, pp. 40-51) but disputed by others (Rothman and Simeone 1975. p. 233; Hensinger 1983) that most radicular pathology in the typical L5/S1 slip involves the L5 nerve root. We suggest that this is the result of a particular form of nerve root canal stenosis, mentioned but not emphasised in previous reports (Eisenstein 1978; Crock 1981).

\section{MATERIALS AND METHODS}

Specimens were collected from the Department of Anatomy and Anthropology of the Tel Aviv University Medical School. The sources of the material were archaeological excavations in the Middle East at sites dating from $1000 \mathrm{BC}$ to the middle of this century. Additionally, contemporary specimens were from skeletons imported from India for teaching purposes.

Ten specimens of spondylolysis without spondylolisthesis were found: five of these were bilateral (Fig. 1), and five unilateral (Fig. 2). Twenty-four specimens showed bilateral complete spondylolysis: in 16 of these the mobile segment was found (Fig. 3). Eight specimens included the sacrum (Fig. 4).

J. G. Edelson, MD, FAAOS, Chief, Department of Orthopaedics Poriya Hospital, Tiberias, Israel 15208.

H. Nathan. MD. Professor and Chief, Department of Anatomy and Anthropology

Sackler School of Medicine. Tel Aviv University. Tel Aviv, Israel.

Requests for reprints should be sent to Dr J. G. Edelson, Kibbutz BeitZera, Emek Hayarden, Israel 15135.

c) 1986 British Editorial Society of Bone and Joint Surgery $0301-620 X / 86 / 4127 \$ 2.00$

\section{FINDINGS}

The area of the spondylitic defect varied from 2 to $9 \mathrm{~mm}$ below the caudal aspect of the pedicle. A consistent finding was a hook-like projection of the proximal lamina at the inlet to the intervertebral foramen (Figs 5 and 6); this is normally the narrowest bony portion of the nerve root canal. If the intervertebral foramen at this level measured $3 \mathrm{~mm}$ or less it was considered definitely stenotic, 3 to $5 \mathrm{~mm}$ was highly suggestive of stenosis and anything over $5 \mathrm{~mm}$ was considered normal (Schneck 1985). The nerve root canals of three of our specimens measured $3 \mathrm{~mm}$ or less (Fig. 7), eight were between 3 and $5 \mathrm{~mm}$ and the rest were within the normal range: thus $11(32 \%)$ of the specimens were either definitely or probably stenotic. Asymmetrical defects were seen in some specimens, with more narrowing on the right side in seven cases and on the left in five. Definite or highly suggestive stenotic measurements were found on both sides in two specimens.

The most dramatic examples of narrowing were seen in those specimens where the end of the hook on the upper segment was approached by an osteophyte from the lower posterolateral margin of the involved vertebra (Fig. 8). The medial portion of the hook contributed to the typically stenotic trefoil appearance of the anterior portion of the vertebral canal in eight specimens (Figs 3 and 9), although the overall anteroposterior diameter of the spinal canal may be increased in spondylolisthesis. This anterior trefoil appearance was also present in specimens with incomplete bilateral defects (Fig. 7). In unilateral defects exuberant bone was seen to narrow the involved side of the anterior portion of the spinal canal in two specimens (Fig. 2).

\section{DISCUSSION}

Although the S1 root may be involved in severe degrees of L5/S1 spondylolisthesis, most authors agree that the L5 root is the source of most radicular pathology (Macnab 1977, p. 54; Cloward 1981). During the "dynasty of the disc" an L4 disc lesion was often postulated to be the 


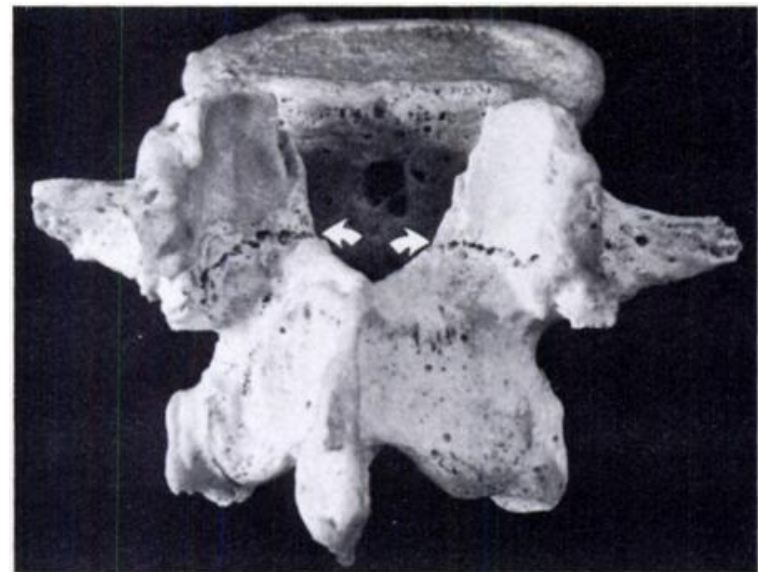

Fig. 1

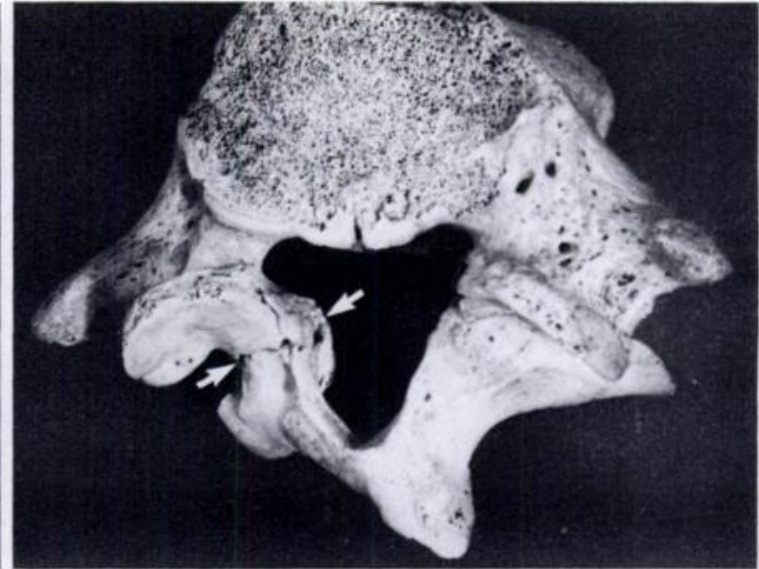

Fig. 2

Figure 1 Postero-anterior view, showing bilateral spondylolysis without spondylolisthesis (arrow indicates defect). Figure 2 Unilateral spondylolysis seen from above: note the narrowing and distortion of the anterior portion of the spinal canal on the side of the defect.

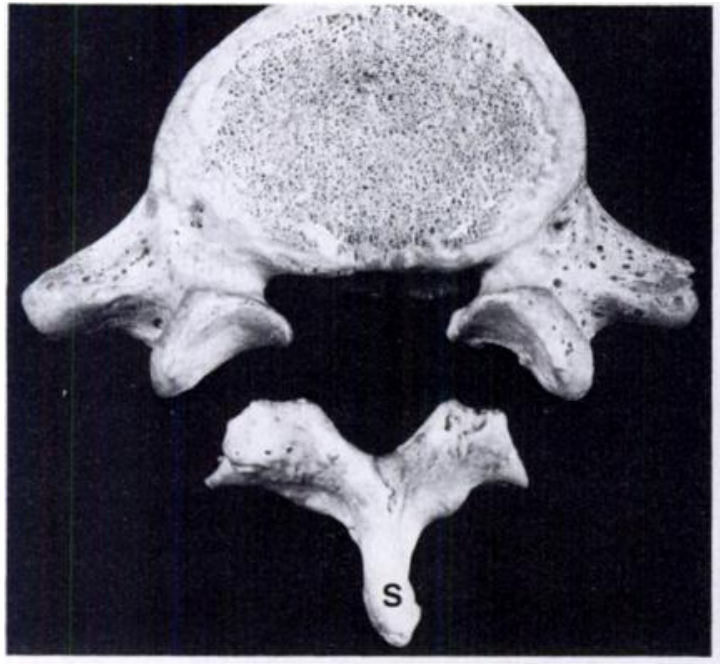

Fig. 3

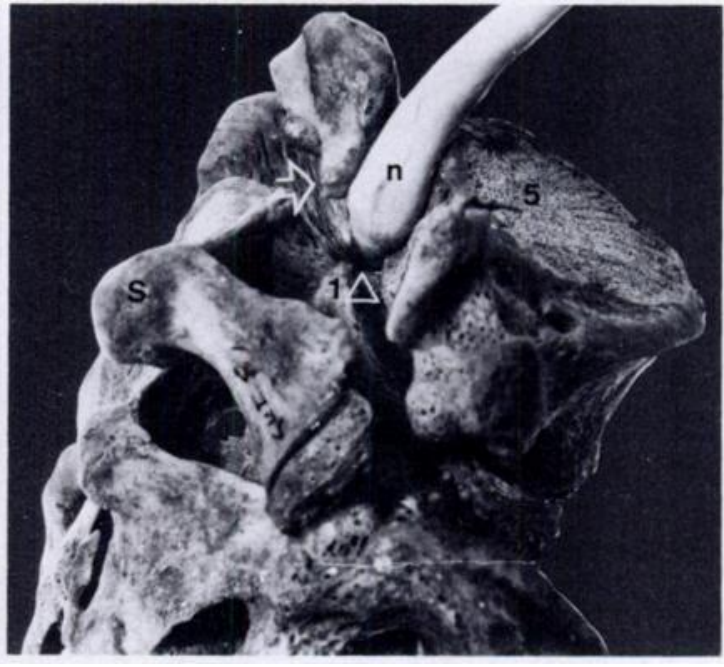

Fig. 4

Figure 3 Bilateral complete spondylolysis seen from above ( $S$. spinous process of a potentially mobile segment). Figure 4 Left oblique view of $L 5$ defect with subjacent sacrum. (5. fifth lumbar vertebra; $l$, first sacral vertebra; $\Rightarrow$, defect; $\triangle$, L5-S disc space: $n$, simulated L5 nerve root: $S$, spinous process of L5).

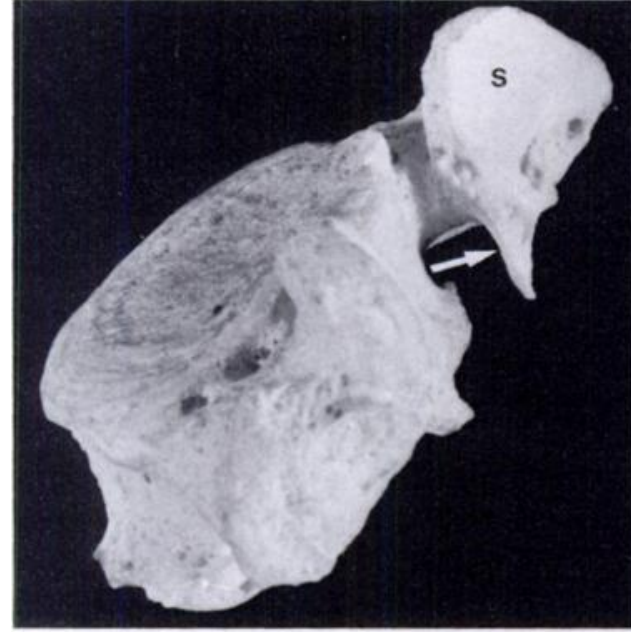

Fig. 5

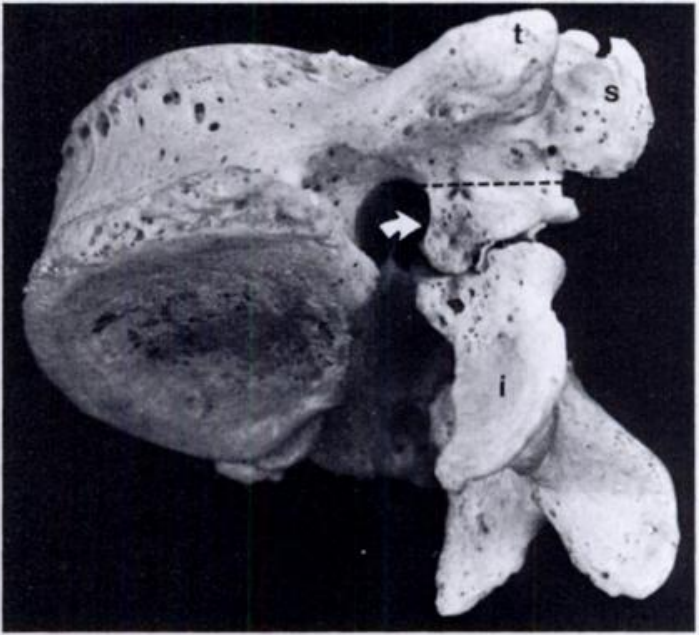

Fig. 6

Figure 5 The arrow indicates the hook-like portion of the lamina ( $s$, superior facet). Figure 6 - The arrow indicates the hook-like portion of the lamina and the dotted line is the proposed line of resection for adequate L5 decompression ( $i$. inferior facet: $s$, superior facet: $t$, transverse process). 


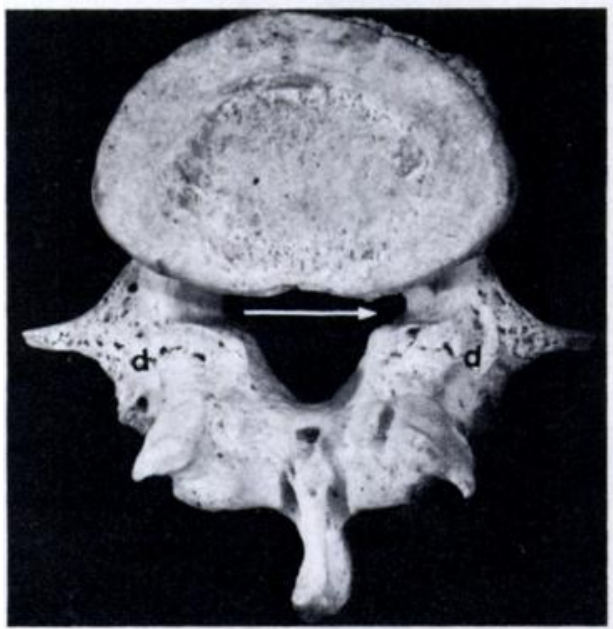

Fig. 7

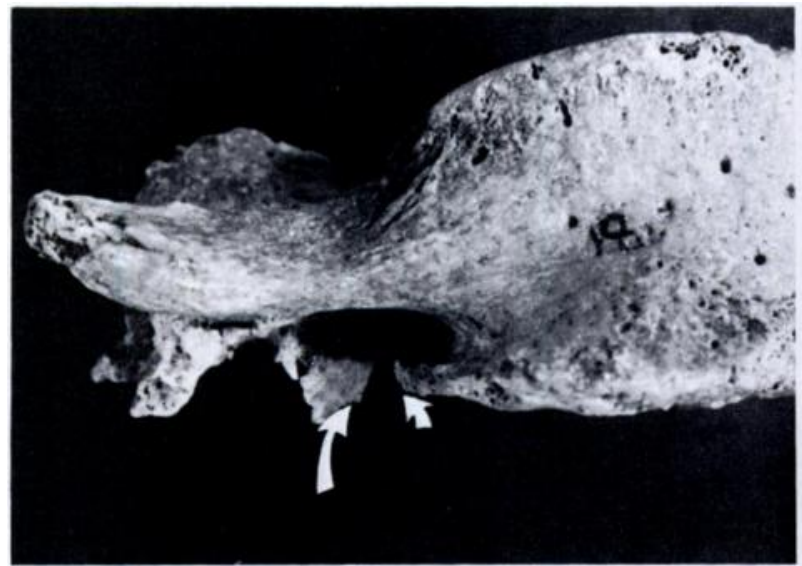

Fig. 8

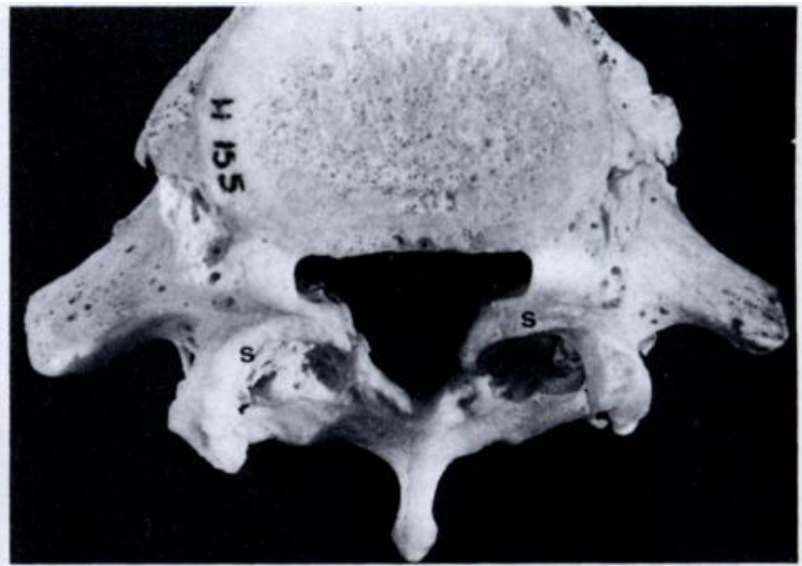

Fig. 9

Figure 7 The white arrow indicates the narrowing of the nerve root canal. From below the trefoil shape of the anterior portion of the spinal canal is clearly seen (d, bilateral but incomplete defect). Figure 8 . Marked narrowing of the nerve root foramen is seen: the end of the hook (left arrow) is approached by a degenerative osteophyte (right arrow) from the posterolateral margin of the same vertebral body (L5). Figure 9 Trefoil shape of the anterior spinal canal seen from above in a specimen with a bilateral complete defect (s. superior facet).

Figure 10 - Simulation of an L5 nerve root $(n)$ trapped in a stenotic canal: the hook-like remnant of the proximal lamina (arrow) and the osteophytes $(o)$ from L5 body are also seen. Figure 11

The arrows indicate excrescences of bone often seen on both sides of a spondylolytic defect and found in combination with exuberant fibrocartilaginous tissue in vivo $(s$, superior facet; $i$, inferior facet; $S$, spinous process of a loose laminar segment).

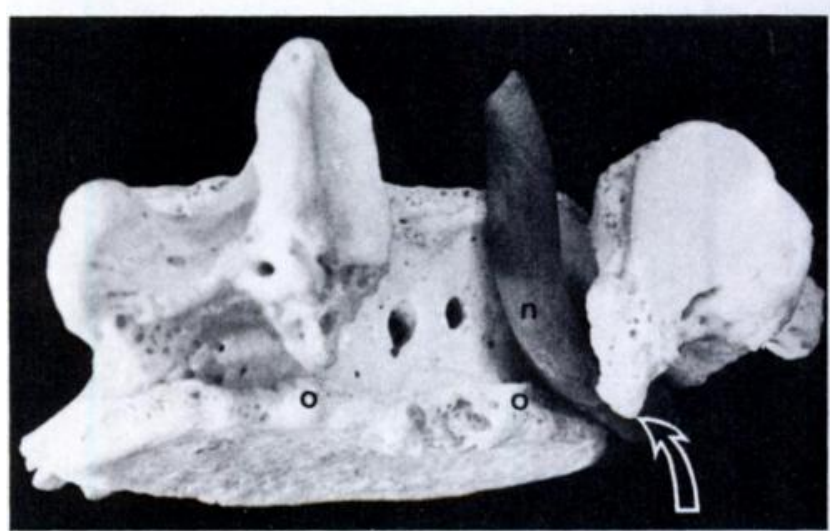

Fig. 10

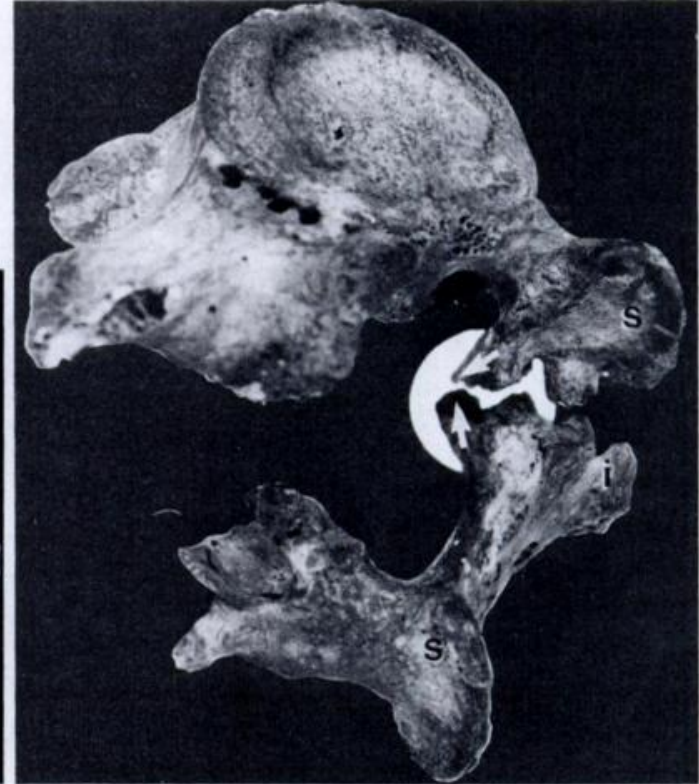

Fig. 11 
source of the problem (Tachdjian 1972, p. 1165; Gill and White 1963) without, however, much biomechanical rationale (Ruge and Wiltse 1977, p. 207) or myelographic evidence (Post 1984, p. 596). We propose a different concept of nerve root compression more consistent with the osseous patho-anatomy; we believe that in selected cases the nerve root is not decompressed by the forward slip of the vertebra as has previously been suggested (Newman 1965; Léger, Bouchard and Maltais 1979) but rather that the nerve, already engaged in a stenotic canal (Fig. 10), is "hooked" forward and increasingly compromised by increasing degrees of slip. This may be due to forward traction on the root itself, posterior pressure from the hook behind, or anterior pressure from the annulus or vertebra below (Fig. 4). The fibrocartilaginous tissues in the area of the lysis, together with the bony excrescences commonly found on both the proximal and distal ends of the neural arch defect (Fig. 11), undoubtedly aggravate the picture of entrapment (Newman 1973; McAfee and Yuan 1982). In older patients osteophytic changes exacerbate the entrapment and increase the tendency to root compromise; this is consistent with the relative rarity of radiculopathy in young people (Turner and Bianco $1971)$ and its greater frequency $(30 \%)$ in older patients (Dandy and Shannon 1971).

A corollary of this explanation of the aetiology of radiculopathy is that the nerve root is best "unhooked" by a complete removal of the residual proximal portion of the deficient lamina up to the base of the pedicle (Fig. 6 ). Such a procedure provides a clear and reproducible end-point for decompression; whether sufficient freeing of the nerve root has been achieved is otherwise subjective and may be difficult to evaluate by eye or by probe alone. Simple removal of the loose neural arch, together with the more obvious fibrocartilaginous tissues in the defect, has proved disappointing (Henderson 1966; Buck 1970; Amuso et al. 1970) and has led to the re-popularisation of in situ fusion procedures.

Careful selection of patients and procedures is, of course, of paramount importance. Few would advocate decompression in the rare case of a very young patient with intractable back pain and no radicular symptoms or signs. However, the best overall results in the largest and most well-documented series to date (Henderson 1966) suggest that adequate laminectomy combined with posterolateral fusion is, in general, the procedure of choice. Such an approach is designed to relieve the two principal causes of pain in spondylolysis and spondylolisthesis, i.e. mechanical instability and nerve root irritation. The results of our work offer anatomical support for such a surgical procedure as well as guidelines for adequate decompression.

\section{REFERENCES}

Amuso SJ, Neff RS, Coulson DB, Laing PG. The surgical treatment of spondylolisthesis by posterior element resection: a long-term follow-up study. J Bone Joint Surg $[\mathrm{Am}]$ 1970:52-A:529 36.

Buck JE. Direct repair of the defect in spondylolisthesis: preliminary report. J Bone Joint Surg [Br] 1970;52-B:432 7.

Cloward RB. Spondylolisthesis: treatment by laminectomy and posterior interbody fusion: review of 100 cases. Clin Orthop 1981; 154 : 74-82.

Crock HV. Normal and pathological anatomy of the lumbar spinal nerve root canals. J Bone Joint Surg [Br] 1981:63-B:487-90.

Dandy DJ, Shannon MJ. Lumbo-sacral subluxation (Group 1 spondylolisthesis). J Bone Joint Surg [Br] 1971:53 B:578 95.

Eisenstein S. Spondylolysis: a skeletal investigation of two population groups. J Bone Joint Surg $[B r]$ 1978;60-B:488 94.

Gill GG, White HL. Surgical treatment of spondylolisthesis without spine fusion. J Bone Joint Surg [Am] 1963;45-A:666.

Helfet AJ, Gruebel Lee DM. Disorders of the lumbar spine. Philadelphia and Toronto: JB Lippincott. 1978.

Henderson ED. Results of the surgical treatment of spondylolisthesis. J Bone Joint Surg $[\mathrm{Am}]$ 1966:48 A:619 42.

Hensinger RN. Spondylolysis and spondylolisthesis. Am Acad Orthop Surg Instr Course Lect 1983:32:132-51.

Léger JL, Bouchard R, Maltais R. Etude radiologique de 305 cas de spondylolyse avec ou sans spondylolisthésis. J Can Assoc Radiol 1979:30:86-9. [Eng. Abstr.]

Macnab I. Backache. Baltimore: Williams \& Wilkins, 1977.

McAfee PC, Yuan HA. Computed tomography in spondylolisthesis. Clin Orihop 1982: 166:62 71.

Newman PH. A clinical syndrome associated with severe lumbo-sacral subluxation. J Bone Joint Surg [Br] 1965:47-B:472 81.

Newman PH. Surgical treatment for derangement of the lumbar spine. $J$ Bone Joint Surg [Br] 1973:55 B:7 19.

Post MJD. Computed tomography of the spine. Baltimore etc: Williams \& Wilkins, 1984

Rothman RH, Simeone FA. The spine. Philadelphia etc: WB Saunders. 1975.

Ruge D, Wiltse LL. Spinal disorders: diagnosis and treatment. Philadelphia: Lea \& Febiger. 1977.

Schneck CD. The anatomy of lumbar spondylosis. Clin Orthop 1985; 193:20-37.

Tachdjian MO. Pediatric orthopedics. Vol. 2. Philadelphia etc: WB Saunders, 1972.

Turner RH, Bianco AJ Jr. Spondylolysis and spondylolisthesis in children and teen-agers. J Bone Joint Surg $[$ Am] 1971:53-A:1298 306. 